\title{
CORRESPONDENCE
}

\section{Nuclear dangers}

Sir - Nils Ove Bielsten (Nature 25 March, p.284) claims on the basis of "fact" that nuclear power plants are safer than hydroelectric, causing far fewer fatal casualties (a rather dubious claim considering comparative risk analysis), "not a single one occurring to people outside the plants (except possibly in accidents due to construction work traffic)". Yet again the impeccable record of nuclear power is invoked and compared with other sources of energy.

Is it not time to recognize and admit to the dangers of the whole chain of supply of nuclear fuel from mining to its eventual and undecided disposal? Uranium mines where studies have been possible, including some in the United States, have recorded mortality rates between 50 and 100 per cent.

Surrounding native American communities also suffer casualties with the additional destruction of their environment and traditional livelihoods, especially painful for people with a traditional respect for the health of the Earth. I believe that it is time for a wider perspective to be taken on large scale projects such as this. Debate over social costbenefit analyses, environmental impact assessments and technology assessments, which are prone to value judgements, does not negate their usefulness.

The casualties of Britain's earlier plutonium/electricity plants are also becoming apparent and substantial sums have been paid in compensation for workers' deaths.

The economics of nuclear plants are not quite as simple as $\mathrm{Mr}$ Bielsten would have us believe either. Left to the electric utilities, as he approves, we find that in the United States no new plants have been ordered for years and several have been cancelled. Plant cost escalations have run up crippling debts for communities and have sent utilities to the federal government for help. In the United Kingdom, it is now suggested that Scottish electricity consumers are paying the price for an unnecessary plant at Torness whose claimed "robust economic case" rests on a possible four-year period when, if coal plants are closed early, it may be useful. Government and independent investigations cast some doubt on even this value to consumers now that costs, need and forecasts are at last being debated.

The writer claims that "nuclear power is the environmentally soundest way of producing the energy that we cannot do without"'. Yet the people of Sweden have voted not to build any further plants beyond those already started. Their closure is already decided and a transition has been embarked on for a programme of energy efficient development ending waste to liberate extra available energy. Renewable energy technologies are increasingly the source of new space heating needs and other requirements.

This approach, and energy efficient developments in the United States, demonstrate the value of demand management as a crucial aspect of energy planning.

Finally, Mr Bielsten's reference to possible benefits of mutation in the population is worrying. If it is a serious point then further debate is necessary.

Martin S. FodOR \section{Complicating SI}

SIR - Like J.A. Nicoll (Nature 10 June, p.450) and probably many others I have considered a simplified notation for physical quantities in terms of SI units.

The appropriate unit is automatically implied by the quantity that must necessarily be specified. Thus the statement that a force is 12 should denote by the absence of units that the SI system is employed and that the force is thus $12 \mathrm{~m} \mathrm{~kg} \mathrm{~s}^{-2}$ or $12 \mathrm{~N}$. Whenever SI is not utilized units must continue to be provided as in $0.237 \mathrm{lb} \mathrm{ft} \mathrm{min} \mathrm{m}^{-2}$. The convenience of omitting units might thus speed the general adoption of SI.

Prefixes (kilo etc.) are not merely clumsy but they conflict with a principal virtue of SI which is coherence. The nuisance of large or small numbers could of course be lessened by the method commonly practised in computer printouts where 67,000 is written as $6.7 \mathrm{E}+4$. However, a simpler notation might be $4 ; 6.7$ which specifies the numbers as read from left to right in increasing detail. The semicolon indicates that the number to the left is the power of ten and the period between 6 and the 7 might in time be dropped by convention. Such numbers are subject to rather obvious and simple rules in algebraic procedures.

In this notation the speed of light is $10 ; 2.99776$ and the electron rest mass $-31 ; 9.109$. For the rather unusual case where a physical quantity has a negative value some further symbolism would be required. Perhaps one might adopt the method used by accountants to indicate net loss rather than net profit. In this case the absolute zero temperature on the centigrade scale would be $(-2 ; 2.73) \mathrm{C}$.

Here the unit would have to be provided since the Kelvin scale can also be employed. Amongst other virtues the latter does not have negative values and one would have $-\infty ; 0$. Which seems a bit odd but could of course also be written conventionally as 0 .

\section{HARALD H. Rossi}

Department of Radiology,

College of Physicians and Surgeons of Columbia University,

New York, USA

\section{German universities}

SIR - Thank you for the splendid review on "Science in West Germany", which was published in Nature on 27 May. There are, however, some additional points on the present situation of German universities which I would like to highlight.

The statement that government support of science will decrease by $\boldsymbol{Z}$ per cent in real terms in 1982 is not quite true for the universities. For instance the universities in NordrheinWestfalen are facing severe budget cuts which give them only 55 per cent of the 1980 budget. For some institutes in the natural sciences this is less money than they had in 1975, and student numbers have risen by some 50 per cent since; readers of Nature will know themselves how much they had to spend on lab-ware and chemicals in the meantime.

Another point is that the measures taken to reform German universities are in fact cutting the numbers of teaching and research personnel at the universities. Only 50 per cent of the young scientists who pursued a university career and "habilitated" themselves in recent years are eligible for a university job in the new frame law-university structure. The Nordrhein-Westfalen measures to concentrate university studies especially in teacher training, which date from March 1982 and were covered in the Nature review, are said to last for at least 5 years in order to transform university jobs into jobs at the Aachen Klinikum; at the end of these 5 years the numbers of personnel in the physics and biology departments at Bonn University will have been reduced by 50 per cent.

Since nobody is talking about student number reductions, please add all this up: what you come out with is a catastrophe. Already experimental work for diploma and doctorate theses in biology often is not financed by the universities, but by money from Deutsche Forschungsgemeinschaft (DFG). Although nobody likes to talk about it aloud, DFG funds are also being spent for teaching jobs and so on. Teaching is severely affected: at Bonn the biology department will have to cut lab courses by one third, the chemistry department is seriously thinking about closing down its central chemicals store. All this makes orderly studies and research impossible. The outlook for Germany's universities is very, very grim.

THOMAS SIMON Bonn, West Germany

\section{Living in the past?}

SIR - It would be unfortunate if the pungent style of S. Blinkhorn's review of The Mismeasures of Man by S. J. Gould, (Nature 8 April, p.506) should weaken the force of his criticism. Like Blinkhorn I think there is much to object to in this book and, for T. J. M. Schopf (Nature 13 May, p.98), I would like to document a few of its substantive faults.

Although he has references as recent as 1979, Gould ignores major studies and references of the 1970 s relevant to the topics he is considering in depth. Consequently, the reader will not learn from Gould's book that most geneticists are not "biological determinists"1,2 nor that modern studies of heredity of cognitive abilities do not rely on a single (mystical) measure of intelligence ${ }^{3}$.

Gould devoted 83 pages to the demolition of nineteenth century claims for an association between cranial capacity and human intelligence and the casual reader undoubtedly will think that he has thoroughly covered this topic. But he omits a critical 1974 review of the subject by Van Valen ${ }^{4}$ which concludes that there probably really is a small positive correlation. Interestingly, Van Valen's conclusion is also ignored by Lewontin (discussing the same subject) in his favourable review ${ }^{5}$ of Gould's book although Van Valen thanks Lewontin for comments (as does Gould).

Gould documents in great detail some blatant errors of the past but, by not coming up to the present, misleadingly implies that it is no different from the past. One would like to know why.

T. EDWARD ReED

Departments of Zoology and Anthropology, University of Toronto, Canada

$$
\begin{aligned}
& \text { Russell, E. S. Genetics 83,s99 (1976). } \\
& \text { Dobzhansky, Th. Persp. Biol. Med. 19, } 156 \text { (1976). } \\
& \text { DeFries, J. C. et al. Nature 261, 131 (1976). } \\
& \text { Van Valen, L. Am. J. phys. Anthropol. 40, } 417 \text { (1974) } \\
& \text { Lewontin, R. C. New York Rev. Books (22 Oct. 1981) }
\end{aligned}
$$

